\title{
Fusarium equiseti Isolated from Lysurus periphragmoides Fruiting Body
}

\section{Rudy Hermawan and Indra Maulana}

Department of Biology, IPB University, Indonesia

*Corresponding Author: Rudy Hermawan, Department of Biology, IPB

University, Indonesia.
Received: January 27, 2022

Published: February 23, 2022

(C) All rights are reserved by Rudy Hermawan and Indra Maulana.

\begin{abstract}
Phyllosphere fungus is a fungus that attaches or moreover enters a tissue of the host. Mostly, the fruiting body that grows on the soil or other substrate openly can be colonized by the phyllosphere fungi. Lysurus periphragmoides was found on the soil. The fruiting body was opened on the head part and the holy structure on the stem part. Fungal isolation from the stem was conducted with surface sterilization before cultivating onto PDA medium. The filamentous fungus (isolate Lyz111) was appeared on isolation medium and identified as Fusarium equiseti using multigene analysis (ITS and LSU regions). This is the first report that Fusarium equiseti have been found as phyllosphere fungus on Lysurus periphragmoides fruiting body.
\end{abstract}

Keywords: Filamentous Fungus; Lysurus periphragmoides; Multigene; Phyllosphere Fungus

\section{Abbreviations}

ITS and LSU

\section{Introduction}

Fusarium incarnatum-equiseti species complex (FIESC), one of 17 species complexes of the genus Fusarium [1], has a few formally described species that are characterized by dorsiventral curvature of macroconidia and abundant chlamydospores [2]. This species complex consists of more than 30 phylogenetic species [1-6] and the members are ubiquitous, some of them take a role as pathogens, saprobes, or secondary invaders $[3,7]$. One of the members of FIESC is Fusarium equiseti. Fusarium equiseti was considered a weak pathogen [8] even considered as an unimportant plant pathogen and a cosmopolitan soil inhabitant $[9,10]$. However, this species still can attack various crops and was recently reported causing Chilli wilt in Kashmir, Northern Himalayas [11]. F. equiseti may produce a variety of toxic secondary metabolites including diacetoyxyscirpinol, moniliformin, and 8-0-methylbostrycoidin [12]. Fusarium equiseti is grouped by O'Donnell, Sutton,
Rinaldi, Gueidan., et al."mendeley":\{“formattedCitation":"(0’Donne ll, Sutton, Rinaldi, Gueidan, et al. [3] in FIESC 14-a. It is also found on substrates or hosts in the form of soil, potato peel, maize husk, hordeum vulgare, Daphne mezereum, sediment, human toenail, and Beta vulgaris [13]. With all the information, the information about Fusarium equiseti substrate or host is still lacking. Thus, this study aimed to describe the morpho-molecular Fusarium equiseti isolated from the fruiting bodies of Lysurus periphragmoides.

\section{Materials and Methods}

Fungal Isolation

The substrate was Lysurus periphragmoides fruiting body [14]. The stem part of Lysurus periphragmoides (Figure 1) was used to isolate the fungi. The surface sterilization was conducted following the protocol from Greenfield., et al. [15]. The stem part of Lysurus fruiting body was sliced carefully in a sterile condition. The part was washed using the surface sterilization solutions, such as sodium hypochlorite $(0.5 \%)$, ethanol (70\%), and sterile distilled water. The Lysurus parts were dried using sterile papers for 1 night in laminar airflow. The Lysurus parts were put on Potato Dextrose 
Agar (PDA) with modification as half potato composition of usual composition. The tissues were incubated at $28 \mathrm{C}$ for $4-7$ days. The mycelia that grew on the medium was transferred into a fresh PDA (normal composition).

\section{Morphological identification}

The mycelium was observed in the PDA medium. The characters such as spore, somatic hyphae, and colony appearance were observed using microscope binocular microscope cs22LED. All characters looked like Hypomycetes fungi or Mitosporic Fungi. Therefore, the morphological identification used special literature book as mitosporic fungi identification book from Kiffer and Morelet [16].

\section{Molecular Identification}

The fungal genomic DNA was extracted using the DNA extraction protocol in Hermawan., et al. [17]. The cetyltrimethyl-ammonium bromide (CTAB) solution was used in this study as a lysis solution. The quality and concentration of the DNA were measured using a spectrophotometer nanodrop. The good quality DNA was used to be continued for amplification. The concentration was around $100 \mathrm{ng} / \mu \mathrm{l}$. Then, the DNA was amplified using two primers, i.e. internal transcribed spacer (ITS) and large subunit (LSU). The ITS primers were ITS 4 (5'-TCC TCC GCT TAT TGA TAT GC-3') and ITS 5 (5'-GGA AGT AAA AGT CGT AAC AAG G-3'). The LSU primers were LROR (5'-GTA CCC GCT GAA CTT AAG C-3') and LR5 (5'-ATC CTG AGG GAA ACT TC-3'). PCR amplification was conducted in a $40 \mu \mathrm{L}$ total reaction. The PCR mixture was composed as $20 \mu \mathrm{L}$ PCR mix of $2 X$ Kappa Fast $2 \mathrm{G}, 2 \mu \mathrm{L}$ of 10 pmol of each primer, $4 \mu \mathrm{L} 100$ ng template DNA, and $12 \mu \mathrm{L} \mathrm{ddH}_{2} \mathrm{O}$. A Thermoline PCR was used for the DNA amplification. The PCR condition was set as follows: initial denaturation at $94^{\circ} \mathrm{C}$ for 2 minutes, denaturation at $94^{\circ} \mathrm{C}$ for 45 seconds, annealing at $55^{\circ} \mathrm{C}$ (for ITS primer) or $56^{\circ} \mathrm{C}$ (for LSU primer) for 1 minute, extension at $72^{\circ} \mathrm{C}$ for 1 minute, and the final extension at $72^{\circ} \mathrm{C}$ for 10 minutes. The cycles from denaturation to the extension were repeated for 30 cycles. The amplicon was estimated on $1 \%$ agarose gels and visualized by the Gel DocTM XR

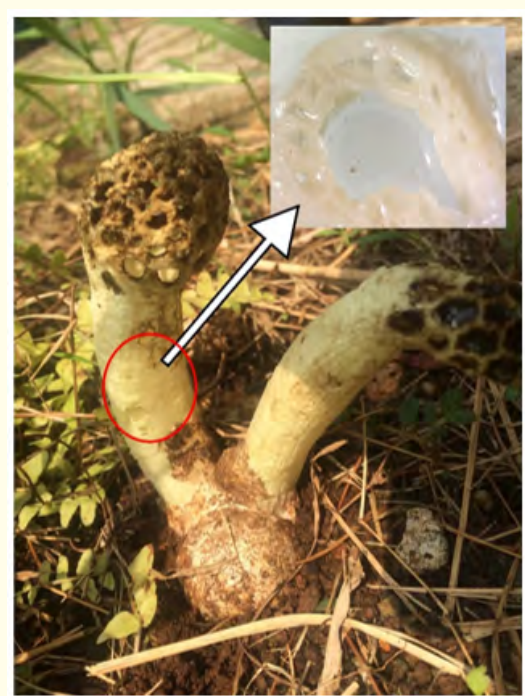

Figure 1: Stem part of Lysurus periphragmoides fruiting body.

system. PCR products were sent to the 1st Base Malaysia company for sequencing using Sanger dideoxy method.

The sequences were assembled using the ChromasPro application. The assembled sequences were deposited into GenBank (https://www.ncbi.nlm.nih.gov/). The sequences were continued to do Basic Local Alignment Search Tool (BLAST) using the NCBI website. The genera will be shown after the BLAST processing. Then, all sequences of Fusarium species (Table 1) were downloaded using current literatures as sequence references [18,19]. Multigene analyses were used to build the phylogenetic tree. The genes of sequences were compiled using MEGA X software which the ITS gene as the first gene and the LSU gene as the second gene. The compiled genes were processed in Clustal X software to get the Phyllip format file [20]. The phylogenetic tree reconstruction used Randomized Axelerated Maximum Likelihood (RAxML) Black Box was generated on CIPRES [21]. The Bootstrap analyses as 1000 replications were used in this phylogenetic tree reconstruction. The Bootstrap (BS) value $\geq 75$ was shown on the branch.

\begin{tabular}{|l|c|c|c|}
\hline \multirow{2}{*}{ Species } & \multirow{2}{*}{ Isolate Code } & \multicolumn{2}{|c|}{ GenBank Accession Number } \\
\cline { 3 - 4 } & & ITS & LSU \\
\hline Aspergillus niger & DAOM 221143 & JN942866 & JN938930 \\
\hline Fuasrium proliferatum & CBS 143592 & LT970804 & LT970804 \\
\hline Fusarium acuminatum & CBS 143612 & LT970802 & LT970802 \\
\hline Fusarium equiseti & CBS 307.94 & MH862468 & MH874117 \\
\hline
\end{tabular}

Citation: Rudy Hermawan and Indra Maulana. "Fusarium equiseti Isolated from Lysurus periphragmoides Fruiting Body". Acta Scientific Microbiology 5.3 (2022): 69-73. 


\begin{tabular}{|l|c|c|c|}
\hline Fusarium equiseti & CBS 219.63 & MH858268 & MH869877 \\
\hline Fusarium equiseti & CBS 126202 & MH864013 & MH875469 \\
\hline Fusarium equiseti & Lyz111 & OM345041 & OM345040 \\
\hline Fusarium gamsii & CBS 143610 & LT970824 & LT970824 \\
\hline Fusarium gamsii & CBS 143609 & LT970823 & LT970823 \\
\hline Fusarium iranicum & CBS 143608 & LT970821 & LT970821 \\
\hline Fusarium iranicum & CBS 143611 & LT970822 & LT970822 \\
\hline Fusarium oxysporum & CBS 143607 & LT970803 & LT970803 \\
\hline Fusarium oxysporum & SJB143 & LC633891 & LC633904 \\
\hline Fusarium oxysporum & SJB232 & LC633892 & LC633905 \\
\hline Fusarium proliferatum & CBS 143594 & LT970805 & LT970805 \\
\hline Fusarium proliferatum & CBS 143599 & LT970806 & LT970806 \\
\hline Fusarium solani & SJB222 & LC633898 & LC633911 \\
\hline Fusarium solani & SJB243 & LC633899 & LC633912 \\
\hline Fusarium solani & SJB62 & LC633897 & LC633910 \\
\hline
\end{tabular}

Table 1: Species, Isolate Code and GenBank Acc. Number in this study.

\section{Results and Discussion}

Isolate Lyz111 was identified as Fusoid fungal group based on the morphological observation (Figure 2). The colony was cottony and whitish milk color. The spore mass looks like pale cream to dark brown. The isolate forms a pale brown to dark brown pigment on PDA medium. The macroconidia were observed on the PDA medium. The microconidia were not observed until 30 day-incubated days. The macroconidium was fusoid shape with 4 to 6 septate. Macroconidium was smooth on the surface and hyaline. Clamydospore was observed when the incubation age was in 21 days more. The macroconidium was 4.2-4.6 $\mu \mathrm{m}$ in width and 25.2-30.4 $\mu \mathrm{m}$ in length. The isolate Lyz111 was isolated by Rudy Hermawan. The Lyz 111 GenBank accession numbers were OM345041 for ITS gene and OM345040 for LSU gene.
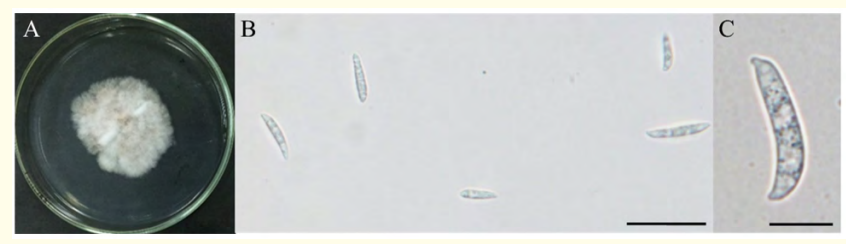

Figure 2: Fusarium Lyz111 isolate on PDA medium for 7 days incubation. (A) Colony on $6 \mathrm{~cm}$ diam. Petri Dish; (B; C) macroconidia. Scale bars: (B) $30 \mu \mathrm{m}$; (C) $5 \mu \mathrm{m}$.
Based on the morphological observation, the spore had the fusoid shape. It can be known as the Fusarium as one of the possible genera for the Lyz111 scientific name. To identify the Fusarium until species, recently it needs more than one gene [18,19,22,23]. Internal Transcribed Spacer (ITS) is the popular and important gene to identify the micro-fungal species [24]. This study used ITS as the first identification gene, then Large Subunit (LSU) as the second gene. The LSU gene was used in Hermawan and Khairillah [20] to identify the Xylaria. But the result of them showed that the LSU gene was not enough strong to identify their fungus until the species name. In our study, we combined the ITS and LSU to make a multigene phylogenetic tree.

The multigene phylogenetic tree of Fusarium species including the Lyz111 isolate (Figure 3) showed that the Lyz111 isolate was identified as Fusarium equiseti with 77 BS value. This value is enough strong to make the Lyz111 isolate as Fusarium equiseti clade. The sister clade of Fusarium equiseti is Fusarium oxysporum. The molecular identification of Fusarium was popular to use many genes for species identification, such as Elongation Factor (Tef), Large Subunit (LSU), RNA polymerase II gene (RPB2), Calmodulin (CAM), and Internal Transcribed Spacer (ITS) [18,19,22,23]. The multigene analysis can show the strong clade structure among the species if as compared with the single-gene analysis. 


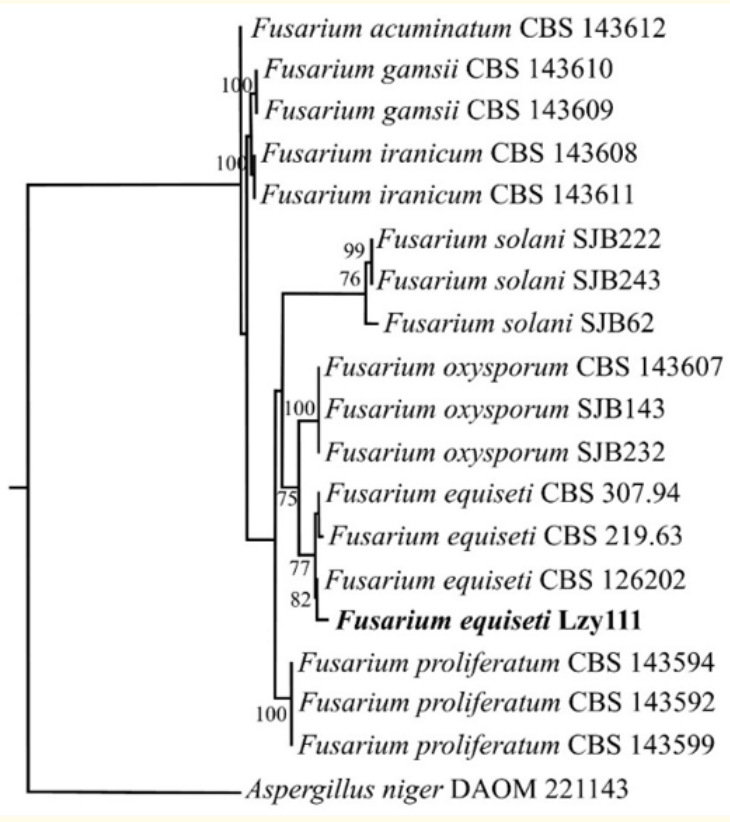

Figure 3: Fusarium phylogenetic tree based on the ITS4/ITS5 and Large Subunit regions (multigene analysis) using RAxML. Bootstrap (BS) $\geq 75$ was shown on the branch. The Fusarium strain Lyz111 must be in bold.

The isolate Lyz111 as Fusarium equiseti could not produce the microconidia on PDA medium. This is supported by the description from Leslie and Summerell [2]. Distinctive from other F. equiseti from Hami., et al. [11] that can produce microconidia on PDA medium. Fusarium equiseti is a cosmopolitan soil that can inhabit some organisms from soil habitat. Therefore, it is possible for Lysurus species is colonized or attached by $F$. equiseti. Some organisms were also potentially infected by $F$. equiseti, such as animal. F. equiseti is reported can cause some poisoning cases to cattle, chickens, ducklings, guinea pigs, mice, pigeons, pigs, rabbits, and rats [25]. Some studies described the toxins that can be produced by $F$. equiseti, such as butanolide [25], beauvericin [26], equisetin [25,27], fusarochromanone [28], and zearalenone (25 Marasas., et al.).

In the plant, F equiseti can be as a saprophytic fungus in root, stem base, and seed part [2]. However, in this study the F. equiseti Lyz111 isolate was found as the phyllosphere fungi in other fungus (L. periphragmoides). This is the first record in F. equiseti ecological characteristic. But the role as phyllosphere fungus in other fungus does not investigate more comprehensive in this study. The role can be a saprophytic, pathogenic, or moreover as endophytic fungus. The continued research about this role is needed to confirm it sooner.
The main purpose for this isolation is to get the Lysurus mycelium in culture medium. But as a result, the Lysurus cannot isolate successfully. The Fusarium equiseti colonies were appeared in our replication and repetition of isolation. The Fusarium was easy to grow faster than the main fungus (Lysurus). Despite the surface sterilization was conducted to minimize the phyllosphere microorganisms harboring during the isolation process. The Fusarium equiseti might enter the Lysurus stem tissue. So, the Fusarium can be survived and isolated into the medium after surface sterilization. Another mushroom such as Xylaria, Hermawan, Safitri., et al. [21] also reported that micro-fungus as Neopestalotiopsis zimbabwana colonized the stromata even the surface sterilization done.

\section{Conclusion}

Isolate Lyz111 isolated from Lysurus periphragmoides stem part was identified as Fusarium equiseti by multigene analysis and supported by morphological identification. This is the first report that F. equiseti was found in L. periphragmoides fruiting body as phyllosphere fungus.

\section{Bibliography}

1. Wang M M., et al. "Fusarium Incarnatum-Equiseti Complex from China". Persoonia 43 (2019): 70-89.

2. Leslie John F and Brett A Summerell. "The Fusarium Laboratory Manual”. Blackwell Publisher (2006).

3. O'Donnell., et al. "Novel Multilocus Sequence Typing Scheme Reveals High Genetic Diversity of Human Pathogenic Members of the Fusarium Incarnatum-F. Equiseti and F. Chlamydosporum Species Complexes within the United States". Journal of Clinical Microbiology 47.12 (2009): 3851-3861.

4. O'Donnell., et al. "Internet-Accessible DNA Sequence Database for Identifying Fusaria from Human and Animal Infections". Journal of Clinical Microbiology 48.10 (2010): 3708-3718.

5. Villani Alessandra., et al. "A Polyphasic Approach for Characterization of a Collection of Cereal Isolates of the Fusarium Incarnatum-Equiseti Species Complex". International Journal of Food Microbiology 234 (2016): 24-35.

6. Maryani N., et al. "Phylogeny and Genetic Diversity of Banana Fusarium Wilt Pathogen Fusarium Oxyxporum f.Sp. Cubense in the Indonesian Centre of Origin". Studies in Mycology 92 (2019): 155-194.

7. Sandoval-Denis M., et al. "Symptomatic Citrus Trees Reveal a New Pathogenic Lineage in Fusarium and Two New Neocosmospora Species". Persoonia 40.1 (2018): 1-25. 
8. Goswami Rubella S and H Corby Kistler. "Heading for Disaster: Fusarium Graminearum on Cereal Crops. Molecular Plant Pathology". Molecular Plant Pathology 5.6 (2004): 15-25.

9. Burgess L W., et al. "Mycogeography of Fusarium: Survey of Fusarium Species in Subtropical and Semi-Arid Grassland Soils from Queensland, Australia". Mycological Research 96.9 (1993): 780-784.

10. Sangalang A E., et al. "Mycogeography of Fusarium Species in Soils from Tropical, Arid, and Mediterraean Regions of Australia”. Mycological Research 99.5 (1995): 523-528.

11. Hami Ammarah., et al. "Morpho-molecular Identification and First Report of Fusarium Equiseti in Causing Chilli Wilt from Kashmir (Northern Himalayas)". Nature Portofolio 11 (2021): 3610-3623.

12. O’Donnell., et al. "Marasas et al. 1984 'Toxigenic Fusarium Species: Identity and Mycotoxicology' Revisited". Mycologia 110.6 (2018): 1-23.

13. Xia J W., et al. "Numbers to Names- Restyling the Fusarium Incarnatum-Equiseti Species Complex". Persoonia 43 (2019): 186-221.

14. Hermawan Rudy., et al. "Morphological Characteristic and Phenetic Relationship of Lysurus Periphragmoides Collected from West Java". Jurnal Biodjati 6.1 (2021): 102-110.

15. Greenfield Melinda., et al. "A Novel Method to Scale up Fungal Endophyte Isolations". Biocontrol Science and Technology 25.10 (2015): 1208-1212.

16. Kiffer E and M Morelet. "The Deuteromycetes-Mitosporic Fungi: Classification and Generic Keys". CRC Press (2011).

17. Hermawan Rudy., et al. "Trichaleurina Javanica from West Java". Jurnal Mikologi Indonesia 4.2 (2020): 175-181.

18. Hassan Oliul and Taehyun Chang. "Morphological and Molecular Characteristics of Fungal Species Asssociated with Crown Rot of Strawberry in South Korea". Molecular Biology Reports 49.1 (2022): 51-62.

19. Torbati Mohsen., et al. "Multigene Phylogeny Reveals New Fungicolous Species in the Fusarium Tricinctum Species Complex and Novel Hosts in the Genus Fusarium from Iran". Mycological Progress 18 (2018): 119-133.

20. Hermawan Rudy and Yuyun Nisaul Khairillah. "Xylaria Sp. The Candle Snuff Fungus from West Java". Jurnal Biota 7.2 (2021): 77-84.
21. Stamatakis A. "RAxML Version 8: A Tool for Phylogenetic Analysis and Post-Analysis of Large Phylogenies". Bioinformatics 30 (2014): 1312-1313.

22. Chehri Khosrow., et al. "Morphological and Phylogenetic Analysis of Fusarium Solani Species Complex in Malaysia. Microbial Ecology". Microbial Ecology 69 (2015): 457-471.

23. Zhu Zhixian., et al. "Identification and Characterization of Fusarium Species Associated with Wilt of Eleocharis Dulcis (Chinese Water Chestnut) in China". Plant Disease 98.7 (2014): 977-987.

24. Schoch Conrad L., et al. "Nuclear Ribosomal Internal Transcribed Spacer (ITS) Region as a Universal DNA Barcode Marker for Fungi". Proceedings of The National Academy of Sciences of The United States of America (2012): 6241-6246.

25. Marasas W F O., et al. "Toxigenic Fusarium Species: Identity and Mycotoxicology". The Pennsylvania State University Press, (1984).

26. Logrieco A., et al. "Beauvericin Production by Fusarium Species". Applied and Environmental Microbiology 64.8, 1998): 3084-3088.

27. Hestbjerg Helle., et al. "Production of Trichothecenes and Other Secondary Metabolites by Fusarium Culmorum and Fusarium Equiseti on Common Laboratory Media and a Soil Organic Matter Agar: An Ecological Interpretation". Journal of Agricultural and Food Technology 50.26 (2002): 7593-7599.

28. Xie W P., et al. "Biosynthesis of Fusachromanone and Its Monoacetyl Derivative by Fusarium Equiseti". Applied and Environmental Microbiology 55.4 (1989): 794-797.

29. Hermawan Rudy., et al. "Neopestalotiopsis Zimbabwana Isolated from Xylaria Stromata”. Biotropika 9.3 (2021): 203-209.

\section{Assets from publication with us}

- Prompt Acknowledgement after receiving the article

- Thorough Double blinded peer review

- Rapid Publication

- Issue of Publication Certificate

- High visibility of your Published work

Website: www.actascientific.com/

Submit Article: www.actascientific.com/submission.php Email us: editor@actascientific.com

Contact us: +919182824667 